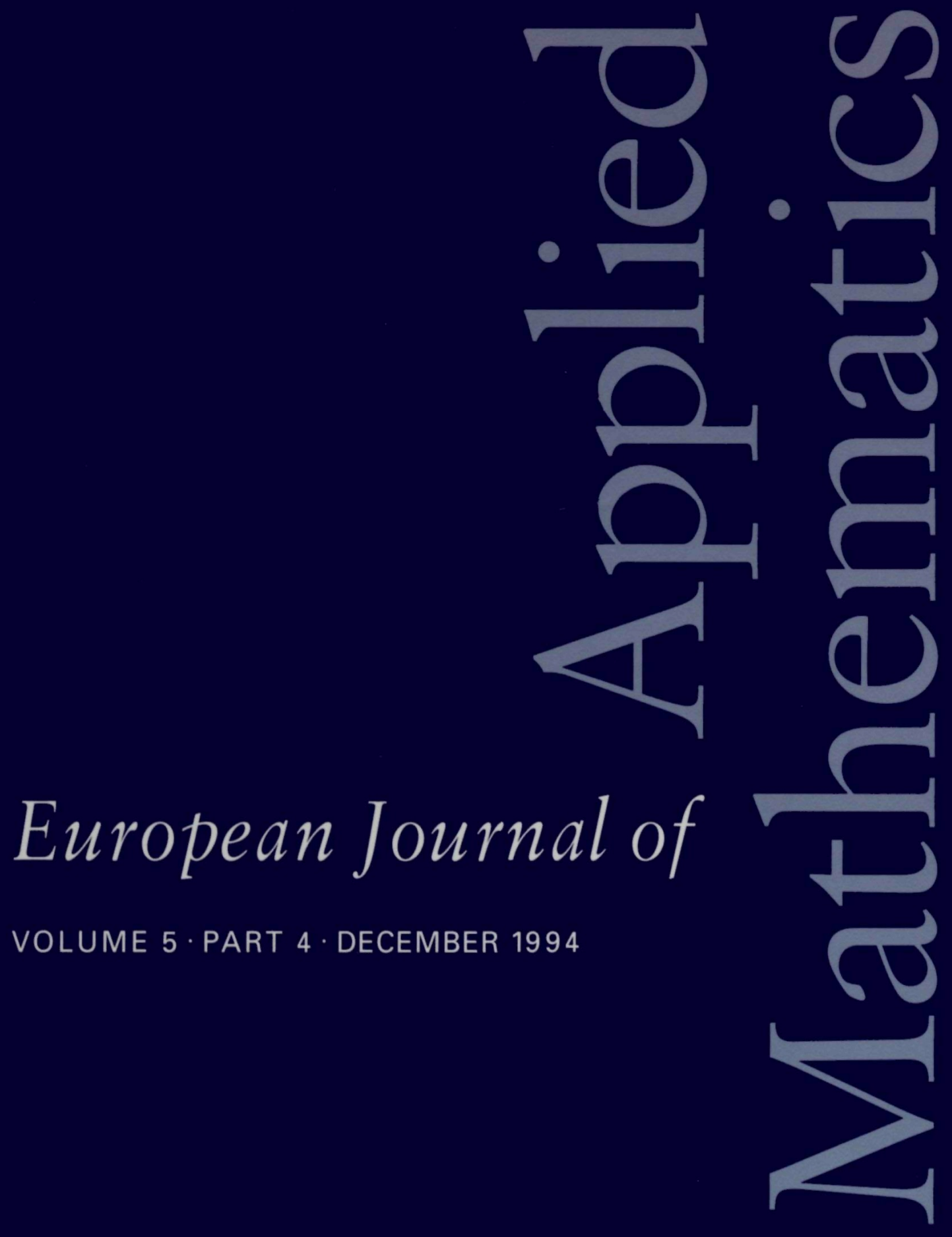

CAMBRIDGE UNIVERSITY PRESS 
DR J.R. OCKENDON

Mathematical Institute, University of Oxford, 24-29 St Giles, Oxford, OX1 3LB, UK

EJAM@VAX.OX.AC.UK

ASSISTANT EDITOR

DR S. D. HOWISON

Mathematical Institute, University of Oxford, 24-29 St Giles, Oxford, OXI 3LB, UK

EJAM@VAX.OX.AC.UK

FAX 44865270515

EDITORS

PROF. A. FRIEDMAN Institute for Mathematics and Applications, University of Minnesota, Minneapolis, MN 55455-0436, USA FRIEDMAN\%CSFSA.CS.UMN.EDU (a) UMN-CS.CS.UMN.EDU

PROF. G. I. BARENBLATT $D A M T P$, University of Cambridge, Silver Street, Cambridge CB3 $9 E W$

PROF. M. CHIPOT

Université de Metz, Département de Mathématiques, Ile du Saulcy, 57045 Metz Cédex 01, France CHIPOT@ARCTURUS.CIRIL.FR

PROF. D. G. CRIGHTON DAMTP, University of Cambridge, Silver Street, Cambridge CB3 9EW

PROF. A. DAMLAMIAN Ecole Polytechnique, Centre de Mathématiques, Route de Saclay, 91128 Palaiseau, France MATDAMLA@EARN.FRPOLY11

PROF. C. M. ELLIOTT Mathematics Subject Group, University of Sussex, Falmer, Brighton BN1 9QH MMFC8@SYMA.SUSSEX.AC.UK

\section{PROF. V. M. ENTOV}

Laboratory of Applied Continuum Mechanics, Institute for Problems in Mechanics, Russian Academy of Science, 117526 Moscow, Russia ENTOV@IPM.MSK.SU
PROF. L. PELETIER Universiteit Leiden, Department of Mathematics, Niels Bohrweg 1, Postbus 9512, NL-2300 RA Leiden, The Netherlands PELETIER@RULCRI.LEIDENUNIV.NL

ASSOCIATE EDITORS

PROF. J. HARPER

Department of Mathematics,

Victoria University of Wellington, PO Box 600, Wellington, New Zealand

JOHN.HARPER@VUW.AC.NZ

DR. A. K. HEAD

Division of Materials Science and Technology, CSIRO, Private Bag 33, Rosebank MDC, Clayton, Victoria 3169, Australia

HEAD@RIVETT.MST.CSIRO.AU

PROF. K.-H. HOFFMANN Lehrstuhl für Angewandte Mathematik, Institut für Angewandte Mathematik und Statistik, TU München,

Dachauerstr 9a, 8000 München 2, Germany

HOFFMANN@APPL-MATH-TUMUENCHEN.DE

PROF. N. KENMOCHI

Department of Mathematics,

Faculty of Education,

Chiba University,

Yayoi-cho 1-33,

Chiba-shi 260, Japan

PROF. LI TATSIEN

Department of Mathematics,

Fudan University, Shanghai, China
PROF. M. PRIMICERIO

Università degli Studi,

Istituto Matematico U. Dini,

Viale Morgagni 67/a,

50134 Firenze, Italy

FISMAT@IFIIDG.FI.CNR.IT

PROF. S. LUCKHAUS

Institut für Angewandte Mathematik, Universität Bonn, Wegelerstrasse 6, 5300 Bonn, Germany SFB256@DBNRHRZ1.BITNET

PROF. B. J. MATKOWSKY Department of Engineering Sciences and Applied Mathematics,

The Technological Institute,

Northwestern University, Evanston, Illinois 60201, USA

MAT@MAT.ESAM.NWU.EDU

PROF. V. V. PUKHNACHOV

Lavrentyev Institute of

Hydrodynamics, Siberian Division

of the Russian Academy of Sciences, Novosibirsk 630090, Russia PUKH@HYDRO.NSK.SU

\section{PROF. D. G. SCHAEFFER}

Department of Mathematics,

Duke University, Durham,

North Carolina 27706, USA

PROF. J. R. WILLIS

Department of Applied Mathematics and Theoretical Physics,

University of Cambridge, Silver Street, Cambridge CB3 9EW

J.R.WILLIS@AMTP.CAM.AC.UK

(C) CAMBRIDGE UNIVERSITY PRESS 1994

\author{
SUBSCRIPTIONS
}

European Journal of Applied Mathematics (ISSN 0956-7925) is published quarterly in March, June, September and December. The subscription price (excluding VAT) of Volume 5, 1994, is $£ 105$ net (USA, Canada and Mexico US $\$ 190)$ post free; single parts cost $£ 28$ net (USA, Canada and Mexico US \$50) plus postage. Four parts form a volume. EU subscribers (outside the UK) who are not registered for VAT should add VAT at their country's rate. VAT registered subscribers should provide their VAT registration number. Orders, which must be accompanied by payment, may be sent to any bookseller, subscription agent or to the publisher: Cambridge University Press, The Edinburgh Building, Shaftesbury Road, Cambridge CB2 2RU, or in the USA, Canada and Mexico to Cambridge University Press, The Journals Department, 40 West 20th Street, New York, NY 10011-4211, USA. Copies of the journal for subscribers in the USA, Canada and Mexico are sent by air to New York to arrive with minimum delay. Second class postage paid at New York, NY, and at additional mailing offices. Japanese prices for institutions (including ASP delivery) are available from Kinokuniya Company Ltd, P.O. Box 55, Chitose, Tokyo 156, Japan.

POSTMASTER: send address changes in USA, Canada and Mexico to European Journal of Applied Mathematics, Cambridge University Press, 110 Midland Avenue, Port Chester, New York, NY 10573-9864.

Claims for missing issues should be made immediately on receipt of the subsequent issue. 